\title{
Chapter 9 \\ Regulating Abuse of SEPs in Mobile \\ Communications Market: Reviewing \\ 1st and 2nd Qualcomm Cases in Korea
}

\author{
Dae-Sik Hong
}

\section{Introduction}

The purpose of this chapter is to analyze the 1st and 2nd Qualcomm cases of the Korea Fair Trade Commission (KFTC) from a legal perspective. A core element of Qualcomm's business model lies in its licensing policies. Qualcomm is a vertically integrated enterprise that engages both in patent licensing and modem chipset businesses. It is divided into the patent licensing division (QTL) and the chipset division (QCT). The KFTC rendered a resolution on the 1st Qualcomm case on July 2009. In this case, the KFTC only reviewed discriminatory factors or conditional rebate factors included in the method of calculating royalty without touching on Qualcomm's business model. With the court proceedings relating to the 1st case still pending, the KFTC initiated another investigation into Qualcomm and sanctioned Qualcomm again in December 2016, which is the 2nd Qualcomm case. In this case, the intrinsic actions that constitute Qualcomm's business model were concerned such as the refusal or restrictions of standard essential patents (SEPs) licenses, the linkage of chipset supply with patent license, and the imposition of unfair and unreasonable licensing terms with the handset manufacturers. ${ }^{1}$

This chapter examines and analyzes some of the competition law issues raised in the two cases. The review consists of the following four parts: the issue of defining relevant markets, the criteria for determining whether there is a violation or evasion

\footnotetext{
${ }^{1}$ 'Joint Comments of the American Bar Association Sections of Antitrust Law, Intellectual Property Law, International Law, and Science And Technology Law on Revisions to the Korea Fair Trade Commission's Review Guidelines on Unfair Exercise of Intellectual Property Rights' (American Bar Association, October 2015) <https://www.americanbar.org/content/dam/aba/ administrative/antitrust_law/at_comments_20151030_ip_guidelines.authcheckdam.pdf>.
}

D. Hong ( $\bowtie)$

Sogang University Law School, Seoul, Republic of Korea

e-mail: dshong@sogang.ac.kr

(C) The Author(s) 2018

A. Bharadwaj et al. (eds.), Multi-dimensional Approaches Towards New Technology, https://doi.org/10.1007/978-981-13-1232-8_9 
of fair, reasonable, and non-discriminatory (FRAND) commitment, the competition law assessment of FRAND commitment infringements, and the theories and establishment of competitive harm. The chapter ends with the comparison with other jurisdictions.

\section{Overview of the 1st and 2nd Qualcomm Cases}

\subsection{Overview of Qualcomm}

Qualcomm consists of three companies that operates two main businesses. The three companies are Qualcomm Incorporated (QI), a US-based patent licensing business operator, Qualcomm Technologies (QTI), a 100\% subsidiary of QI, operating a modem chipset business, and CDMA Technologies Asia-Pacific PTE Limited (QCTAP) that sells a modem chipset as a wholly owned subsidiary of QI. The two main businesses are patent licensing business and modem chipset business. The patent licensing business is a business that collects royalties from licensees while maintaining SEPs in the mobile communications industry. Modem chipset business is a business that manufactures and sells modem chipsets using SEPs.

Given the finding of the facts in the KFTC decision, Qualcomm's business model is characterized as integration of two main businesses. One of the key finding is that Qualcomm is a vertically integrated enterprise that engage both in patent licensing and modem chipset businesses. Another key finding is about Qualcomm's licensing policies according to which Qualcomm refuses or restricts to license SEPs to rival chipset makers while it licenses only to cellphone manufacturers. Some call this practice 'level discrimination' between component level and device level. ${ }^{2}$

Qualcomm was accused of using this business model as a leveraging tool in competition and negotiations. Qualcomm manufactures modem chipsets using an internal patent license, but competitors should manufacture such chipsets without a patent license. As a result, Qualcomm has a competitive advantage over its competitors. Cellphone manufacturers using competitors' modem chipsets are vulnerable to Qualcomm's threat of patent infringement. In addition, Qualcomm will have increased bargaining power with cellphone manufacturers, allowing it to sell their modem chipsets or license SEPs to cellphone manufacturers on favorable terms.

\subsection{Summary of the 1st Qualcomm Case}

The KFTC's 1st Qualcomm case investigation was launched in February 2006. In April 2006, on-site investigation was conducted on Qualcomm Korea and domestic

\footnotetext{
${ }^{2}$ Sang-Seung Yi, 'Responsibilities of FRAND- Encumbered SEP Owners under Competition Law' (AsLEA 12th Annual Conference, Seoul, June 2016).
} 
handset manufacturers. In April and June 2006, the KFTC received complaints against Qualcomm from two domestic companies and two foreign companies ${ }^{3}$ for alleged violations of the Monopoly Regulation and Fair Trade Act (MRFTA) of Korea and sent an examination report ${ }^{4}$ to Qualcomm in February 2009. The KFTC's full commission held six deliberation meetings from May 2009 to July 2009. On 23 July 2009, Qualcomm was imposed with a fine of 273.1 billion won (approximately 218 million US dollars) with corrective measures. The written decision on this case was completed on 30 December $2009 .^{5}$

The Seoul High Court, which has exclusive jurisdiction in the first instance, heard an appeal filed by Qualcomm, and rendered a ruling on 19 June $2013 .{ }^{6}$ As a result of the ruling, most of Qualcomm's claims were dismissed except to cancel a little part of the corrective actions. The case is currently pending in the Korean Supreme Court.

\subsection{Summary of the 2nd Qualcomm Case}

While 1st case is still pending in the Korean Supreme Court, the KFTC initiated another investigation into Qualcomm. This time the major opponent was a domestic company, Samsung. The KFTC's 2nd Qualcomm case investigation was launched in August 2014, and on-site investigation of Qualcomm Korea was conducted in March 2015. The KFTC sent an examination report to Qualcomm in November 2015. Qualcomm submitted a written opinion in May 2016, and the KFTC held four deliberation meetings from June to October 2016. The KFTC was concerned as being seen favorable to the domestic company at first. However, as the case progressed, foreign companies such as US-based Intel, Apple, NVidia, Taiwan-based MediaTek, and China-based Huawei cooperated with the KFTC, which helped the KFTC feel comfortable. Qualcomm filed a motion for consent decree in November 2016, which was dismissed from the KFTC in December 2016. The KFTC imposed a fine of 1.03 trillion won (approximately 850 milion US dollars) with corrective measures on 21 December 2016. The written decision on this case was completed on 20 January $2017 .^{7}$

In February 2017, Qualcomm filed an appeal lawsuit and application for suspension of enforcement with the Seoul High Court against the decision. The Seoul High Court dismissed the application for suspension on 4 September 2017. The appeal lawsuit is currently ongoing at the Seoul High Court.

\footnotetext{
${ }^{3}$ Those are Qualcomm's rival US modem chipset companies like Broadcom and Texas Instrument which had interest in entering the modem chipset market.

${ }^{4}$ The report corresponds to a Statement of Objections in the European Union (EU).

${ }^{5}$ KFTC Decision, No. 2009-281, 2009Jisik0329 (S. Kor.).

${ }^{6}$ Seoul High Court 2010 Nu3932, Order dated 19 June 2013 (S. Kor.).

${ }^{7}$ KFTC Decision, No. 2017-025, 2015 Sigam2118 (S. Kor.).
} 


\subsection{Background of the Cases}

The 1st and 2nd Korean Qualcomm cases have been set at different stages of mobile communications standard technology developments. Mobile communications standard technologies have been developed from the 1 st generation through the 2 nd and the 3rd generation to the 4th generation. With regard to the 2nd generation, South Korea was deeply associated with and highly dependent on Qualcomm's technologies. At the time of the first adoption of CDMA technology in Korea, Qualcomm was a small company. But it grew significantly in the market as Korea's market expanded.

In 2009, when the 1st Qualcomm case decision was made, services based on the CDMA standard, the 2nd generation mobile communications technology, and services based on the CDMA2000 and WCDMA standard, the 3rd generation mobile communications technology coexisted. Qualcomm has been a leader in CDMA technology since its foundation in 1985. Korea selected the CDMA system as the 2nd generation mobile communications system in 1993. SK Telecom, Korea's number 1 mobile communications provider, succeeded in commercialization of the world's first CDMA based mobile communications service in 1996. The Telecommunications for Technology Association (TTA) in Korea established CDMA mobile communications standards based on seven patents held by Qualcomm in 1996. Qualcomm has 90\% of SEPs in CDMA technology.

Korea's mobile operators are actively involved in the introduction of 3rd generation mobile communications services. In December 2000, three operators, SK Telecom, KTF and LG Telecom participated in the service provision project using the IMT-2000 standard based on CDMA2000. SK Telecom and KTF have begun to provide 3rd generation mobile communications services based on WCDMA standard. Qualcomm accounts for $27 \%$ of SEPs in WCDMA technology. However, at the time of 2009, 3rd generation mobile communications services were not yet active, and Qualcomm's SEPs accounted for a significant portion of the CDMA standard used in 2nd generation mobile communications services, which still had high utilization rates. In this context, the 1st Qualcomm case focused on Qualcomm's patents included in the CDMA standard as the relevant technology market, and the relevant component market was limited to domestic CDMA modem chipset market and domestic CDMA RF chip market.

The 2nd Qualcomm case decision was made in 2016, when mobile services were transitioning from 3rd generation mobile communications based on WCDMA standard to 4th generation mobile communications based on the LTE standard. The development of the 4th generation mobile communications technology originated from the WiMax standard developed by the Institute of Electrical and Electronics Engineers (IEEE) since 2004, which influenced the 3rd Generation Partnership Project (3GPP) to establish the LTE standard in 2008. In Korea, LTE service started in July 2011. Qualcomm has 16\% of the SEPs included in the LTE standard. 
The proportion of Qualcomm's patents in mobile telecommunications standards has been gradually decreasing from 2 nd generation to 3rd generation, and the proportion of modem chipsets in handsets is decreasing as handsets evolve into smartphones. Nonetheless, there was growing dissatisfaction with the chipset makers and handset makers as Qualcomm continued to maintain its superiority in patent licensing negotiations while achieving high royalty revenues. Under this circumstance, in the 2nd Qualcomm case, Qualcomm's mobile SEP license markets for CDMA, WCDMA and LTE standards were examined as a relevant technology market respectively, and the modem chipset markets for CDMA, WCDMA and LTE standards were considered as a relevant component market, correspondingly.

\section{Conduct Types in Question}

\subsection{Conduct in 1st Case}

In the 1st Qualcomm case, there were two types of conduct related to licensing for handset manufacturers and one type of conduct related to selling handset components. The types of behaviors related to licensing for handset manufacturers are (1) discrimination on collecting royalties for licenses, (2) conditional rebates on modem chipsets and RF chips, and the type of behavior associated with selling handset components and (3) imposition of royalties even after expiration of patents.

\subsubsection{Discrimination in Collecting Royalties}

The KFTC concerned three types of acts for discrimination. This is due to: (i) discrimination against domestic-model handset using non-Qualcomm chipsets by price-netting program; (ii) discrimination against export-model handset using non-Qualcomm chipsets by royalty rate discount program; and (iii) discrimination against non-Qualcomm chipset users by royalty cap program. ${ }^{8}$ The KFTC acknowledged that these practices produced discriminatory effects between Qualcomm's modem chipsets and its competitors' modem chipsets to handset makers even if it is the same handset maker by making them pay higher royalties when using modem chipsets other than Qualcomm's.

This conduct type is related to the non-discriminatory element of FRAND. In order to determine whether the conduct in question constitutes an act of

\footnotetext{
${ }^{8}$ Shiwon Ryu, 'Regulation of Anticompetitive IP Licensing Practices Studied in Qualcomm Case' (2011) 9 Korea University Law Review $81<$ http://koreauniversitylawreview.korea.ac.kr/xe/? module=file \&act=procFileDownload \&file_srl=997\&sid=731549d1e80c4c3ce235d9d83d4cf712\& module_srl=115>.
} 
discrimination in price or trading conditions under the MRFTA, a separate analysis is required to determine the 'discriminatory' conduct element. The KFTC's Guidelines for Review of Abuse of Market Dominant Position (Abuse Guidelines) does not include any standards by which to judge the behavioral element of discrimination. However, the KFTC referred to the standards specified in the Guidelines on Review of Unfair Trade Practice (UTP Guidelines) in reaching a decision even though the analysis of unfair trade practices may be less rigorous than that of abuse of dominance. ${ }^{9}$

\subsubsection{Conditional Rebates on Modem Chipsets and RF Chips}

In this case, the problematic rebate payment method is a retrospective, progressive payment imposed on handset manufacturers on the condition that Qualcomm chipsets are purchased at a certain rate or on a certain scale. The KFTC acknowledged that this act caused cumulative exclusionary effects along with royalty discrimination on competitors that manufacture modem chipsets and RF chipsets.

\subsubsection{Imposition of Royalties Even After Expiration of Patents}

Qualcomm set up and maintained a provision that imposed royalties as much as $50 \%$ of the applicable royalty rate for invalid or expired patents. The KFTC acknowledged that it would lead to a disadvantageous effect on the counterparts by increasing the risk of being taken unfair gains when implemented.

\subsection{Conduct in 2nd Case}

In the 2nd Qualcomm case, there was one type of behavior related to the conditions under which licensing to the rival modem chipset manufacturers is allowed, and two types of behavior related to the conditions under which the licenses for the handset manufacturers are given. The conduct type related to the licensing of rival modem chipset manufacturers is (1) an act of refusing or restricting to license SEPs to rival chipset makers, and the types of conduct related to the licenses for the handset manufacturers are (2) an act of linking chipset supply with patent license with handset makers and (3) an act of imposing unfair and unreasonable licensing terms with handset makers.

\footnotetext{
${ }^{9}$ Mark Furse, Antitrust Law in China, Korea and Vietnam (Oxford University Press 2009) 259.
} 


\subsubsection{Refusing or Restricting to License SEPs to Rival Chipset Makers}

Before 2008, while licensing to both rival modem chipset makers and handset manufacturers, Qualcomm has not closed the possibility of licensing to rival chipset makers but restricted the scope of the license to them by imposing post-sale restriction on the right to use chipset, allowing to sell only to handset makers having license agreement with Qualcomm. It can be explained as multi-level licensing ${ }^{10}$ strategy in order to prevent the application of the patent exhaustion principle. ${ }^{11}$ However, after 2008, it refuses to license rivals and only offers agreements not to file lawsuits or to reserve lawsuits (covenant not to sue, covenant to exhaust or stand still). The change in policy in 2008 seems to be a response to the uncertainty in the applicability of patent exhaustion principle caused by the decision in Quanta case by the Supreme Court of the US in $2008 .^{12}$

\subsubsection{Linking Chipset Supply with Patent License with Handset Makers}

Qualcomm licenses SEPs to licensees only when it supplies its modem chipsets to them, refusing to supply chipsets when licensees do not enter into the patent license agreement. This can be summarized as a policy that there are no chips without a prior license which is also called 'no license, no chips' policy. ${ }^{13}$ The KFTC acknowledged that Qualcomm actually used the threat of terminating the supply of

\footnotetext{
${ }^{10}$ Multi-level licensing refers to a practice that a patentee offers to license to a chipset maker or component maker on condition that it sells only to end-user equipment makers who have themselves paid for a license. Karl D. Belgum, 'The Next Battle Over FRAND: The Definition of FRAND Terms and Multi-Level Licensing' (2014) Berkeley Law <https://www.law.berkeley.edu/ files/Belgum_Karl_IPSC_paper_2014.pdf>.

${ }^{11}$ Roberto Grasso, 'Selected Issues In SEP Licensing In Europe: The Antitrust Perspective' in Ashish Bharadwaj, Vishwas H. Devaiah and Indranath Gupta (eds) Complications and Quandaries in the ICT Sector (Springer Singapore 2017) $86<\mathrm{https}: / / \mathrm{www}$. springer.com/in/book/ 9789811060106> (stating that the strategic refusal to license at component level is based on the patent exhaustion doctrine); Under patent exhaustion principle, one who purchases from a patentee or licensee in an authorized sale obtains the patented product free and clear of patent rights; Quanta Computer, Inc. v LG Electronics, Inc. (2008) Supreme Court of the United States, 553 US 617.

${ }^{12}$ In Quanta, the court held that ' $[\mathrm{t}$ ]he longstanding doctrine of patent exhaustion provides that the initial authorized sale of a patented item terminates all patent rights to that item'. But it remains unclear as to what extent a patentee can use a conditional license to impose restrictions on downstream purchasers; Richard Stern, 'Quanta Computer Inc v LGE Electronics Inc: Comments on the Reaffirmance of the Exhaustion Doctrine in the United States' (2008) European Intellectual Property Review 527.

${ }^{13}$ Greg Sivinski, 'District Court Denies Motion to Dismiss FTC Section 5 Complaint Against Qualcomm' (Competition Policy International, 2017) <https://www.competitionpolicyinternational. com/wp-content/uploads/2017/08/North-America-Column-August-Full-4.pdf $>$.
} 
modem chipsets as negotiation leverage in the process of license negotiations with handset companies. ${ }^{14}$

\subsubsection{Imposing Unfair and Unreasonable Licensing Terms}

Roughly speaking, unfairness element refers to transparency and good faith in the negotiation process and unreasonableness element refers to balancing mechanism with conflicting interests. The unfairness or unreasonableness of arrangements made with handset makers has been examined in three aspects. The first aspect is that Qualcomm does not present the list of patents when licensing and providing portfolio licenses including SEPs and other non-SEPs (comprehensive portfolio license). The second aspect is that it does not provide good faith negotiation procedures and imposes unilaterally-decided licensing terms in which royalties are based on the entire handset sales prices (unilateral licensing terms). The third aspect is that handset makers are required to license their patents to Qualcomm's customers without fair compensation (royalty-free cross-grant terms).

\subsection{Relationship Between Conduct Types of Two Qualcomm Cases}

Of the types of conduct covered in the 2nd Qualcomm case, there are issues not covered in the 1 st Qualcomm case because the 2 nd case reflects changed situations. However, some issues from the conducts of the 2 nd case arise from the continuing situation in the 1 st case and have close relationship with the conduct types of the 1 st case.

The 2nd case conduct type of refusing or restricting to license SEPs to rival chipset makers has been strengthened since 2008 resulting from change in licensing policy from 'component-level and device-level parallel policy' (multi-level licensing) to 'device-level only policy' (level discrimination), which was not reviewed in the 1st case. Practice of linking chipset supply with patent license with handset makers in the 2 nd case started from 1993, but was not dealt with in the 1 st case.

Qualcomm's practice of calculating royalties based on the entire handset sales prices (entire market value rule) existed in both the 1st and 2nd cases. In relation to this practice, royalty calculation formula and its adoption process were reviewed in the 2nd case, while only discriminatory factors or conditional rebate factors included in the method of calculating royalty were reviewed in the 1 st case.

\footnotetext{
${ }^{14}$ Korea Fair Trade Commission (KFTC), 'Strict Sanctions on Qualcomm's Abuse of Cellular SEPs' (2016) <https://www.qualcomm.com/documents/kftc-issuedpress-release-dated-december28-2016-unofficial-english-translation>.
} 
The KFTC rested its findings on the provision prohibiting 'unfair interference with another's business activities' under Article 3-2(1) (Abuse of Market Dominance) of MRFTA and Article 5(3) of the Enforcement Decree. In some conduct types, 'abuse of superior trading position' under Article 23(1) (Unfair Trade Practices) of the MRFTA and Article 36(1) of the Enforcement Decree was also applied.

\subsection{Expected Effects on Qualcomm'Business Model}

In the 1st case, Qualcomm's business model was not influenced, only methods of operation being affected. The remedies of the 1 st case could not address problems of entry barrier for potential entrants into modem chipset markets effectively, which brought about additional complaints from the competitors despite the outcome of the 1 st case.

In contrast, the remedies of the 2nd case impact directly on Qualcomm's business model. To comply with the remedies requiring Qualcomm to engage in good faith negotiation with rival model chipset makers and handset makers, Qualcomm should change its licensing policy fundamentally. The required policy change may affect the methods to calculate royalty fees which are the key for Qualcomm to earn a lot of profits despite decreasing influence of Qualcomm in the LTE standard.

\section{Some Competition Law Issues}

\subsection{Issue of Defining Relevant Markets}

A common feature of the 1 st and 2 nd cases related to the relevant market definition is distinction between technology market and goods market. Main goal of market definition is to understand the competitive constraints systemically and thus the degree of market power. ${ }^{15}$ As Qualcomm is a vertically integrating enterprise active in both technology and goods markets, the market definition is required to make distinction between two markets.

Two issues have been raised regarding Qualcomm's SEPs license markets. One issue is whether to define a separate market for each mobile telecommunications technology standard. Another issue is whether to consider a number of Qualcomm's SEPs included in one technical standard as the same relevant market. The KFTC decided that different communications standards would make different markets based on the fact that CDMA, WCDMA and LTE standards cannot be replaced

\footnotetext{
${ }^{15}$ David Evans, 'Lightening Up on Market Definition' in Einer Elhauge (eds), Research Handbook on the Economics of Antitrust Law (Edward Elgar 2010).
} 
with one another. In addition, the KFTC determined that Qualcomm's SEPs should constitute a cluster market, not a discrete market within the standard. That's because each of Qualcomm's technology included in the same standard has a relationship of technical and transactional complements with one another.

Regarding the delineation of the relevant geographical market, there is a question of whether the geographical area is domestic or international. While the geographical area was domestic in the 1st case where only CDMA standard was reviewed, it was the international market in the 2nd case where all of the CDMA, WCDMA, and LTE standards were reviewed. What makes the difference is that the CDMA standard could not be replaced outside the domestic market, but the WCDMA or LTE Standards have been internationally recognized with few substitutes.

\subsection{Determining Whether FRAND Commitment Is Violated or Evaded}

A FRAND commitment is made when the patent owner commits to the standard setting organization (SSO) that it will negotiate on FRAND terms for licensing of patented technology prior to the selection of the patented technologies for inclusion in the standard. A FRAND-encumbered SEP holder is under a pre-contractual obligation to negotiate the license in good faith, not under a contractual duty to grant a FRAND license to any potential licensee. ${ }^{16}$

Generally speaking, the specific meaning of FRAND can only be established in concrete situations, in particular taking into account the positions of the licensor and the licensee. ${ }^{17}$ The elements that make up the FRAND terms can be divided into fairness and unreasonableness elements and non-discriminatory element. The non-discriminatory element of FRAND was reviewed in the 1st case, while the fairness and unreasonableness elements of FRAND were reviewed in the 2nd case.

With regard to whether Qualcomm's conduct in the 1st case violated non-discriminatory element of FRAND, the KFTC regarded its finding of discrimination as a violation of FRAND commitment. It appears not to have precisely interpreted the boundary of Qualcomm's FRAND obligation, nor it did provide clear guidance as to how Qualcomm's royalty scheme was a FRAND violation. ${ }^{18}$ The separate issue is whether setting a different price to even a single firm pursuant

\footnotetext{
${ }^{16}$ Dae-Sik Hong, 'A Review of Korean Competition Law and Guidelines for Exercise of Standard-related Patents' (2015) The Journal of Korean Law 127.

${ }^{17}$ Damien Geradin and Miguel Rato, 'Can Standard-Setting Lead to Exploitative Abuse? A Dissonant View on Patent Hold-Up, Royalty Stacking and the Meaning of FRAND' (2007) European Competition Journal 101.

${ }^{18}$ Yoonhee Kim and Hui-Jin Yang, 'A Brief Overview of Qualcomm v Korea Fair Trade Commission' (2015) 1 Competition Policy International Antitrust Chronicle <https://www. competitionpolicyinternational.com/file/view/7352>.
} 
to specific conditions may count as discrimination. Both the KFTC and the Seoul High Court decided in the affirmative, but based on different reasons. ${ }^{19}$

The issue that Qualcomm's conduct in the 2nd case violated fairness and unreasonableness elements was illuminated in three respects. The first is normality of licensing method. The KFTC acknowledged the fact that the market-dominant vertically integrated operator in both technology markets (especially SEPs) and goods market refuses to license modem chipset makers only licensing to handset makers does not correspond to normal trading practices.

The second is fairness in negotiation and set-up or modification of prices or other trading conditions. This is a review of Qualcomm's compliance with the FRAND commitment from the perspective of the trading process. The KFTC considered that the practice of linking modem chipset supplies with licensing agreements is against a duty of complying with good faith negotiation process.

The third is the reasonableness of prices or other trading conditions. This is to assess the rationality of the trading contents. The KFTC determined that the licensing terms were unreasonable in light of comprehensive portfolio licensing, unilaterally-defined royalty terms, and royalty-free cross-grant terms.

\subsection{Competition Law Assessment on FRAND Commitment}

It is questionable whether FRAND commitment infringements are anticompetitive per se or presumptively anticompetitive subject to rebuttal. This is a question of whether additional stage is needed to assess anti-competitiveness after the FRAND commitment infringements are found out. The KFTC views that infringing FRAND commitment is likely to be anticompetitive by itself, but it goes further to assess anti-competitiveness.

Argument that FRAND commitment infringements are anticompetitive bases the understanding that FRAND commitments are institutional competitive constraints by itself. Essentiality means that there are no substitutes in specific technologies. Once standard setting is made, it results in disappearance of competitive constraints in the same standard market. Other substitutable technologies before the standard setting, if any, are excluded artificially by standard setting that would have otherwise existed as competitive constraints in the process of competition to be included in the specific technology standard.

\footnotetext{
${ }^{19}$ For critics for deciding whether there is discrimination based on comparison of different prices to 'one buyer' conditioned upon the amount of purchases, see Jinyul Ju, 'Recent developments in Korean antirust cases concerning FRAND-encumbered standard essential patents' (2015) 8(2) Jindal Global Law Review 221.

However, in this case, it can be argued that discrimination is based on the fact that the effects are attributed to Qualcomm and its competitors in the modem chipset markets in a discriminatory way.
} 
Influence of SEPs can be lessened when (i) standard is not the only one but with substitutable standard already existing and/or (ii) competition with goods not using such standard is available or entry of new goods are possible in the market. Before the adoption of the new standard, there might be competition between substitutable technologies for the inclusion of the new standard. This is competition 'for the market' as opposed to competition 'in the market'. Despite the end of competition for the same market with the adoption of the new standard, there could still be competitive pressures from inter-standard competition. But there remains no competition in the market if there is no inter-standard competition at all. This is what happened to mobile communications standard technology in the 4th generation. In the mobile communications market, inter-standard competition existed in the 2nd generation standard (CDMA-19\%, GSM-81\%), then such competition was weakened in the 3rd generation (WCDMA-85\%, CDMA 2000-13\%, TD-SCDMA-2\%), and disappeared by being unified to LTE in the 4th generation standard. Especially, in the LTE standard there are no alternative standards nor components alternative to modem chipsets using the LTE standard. Thus, an SEP holder has incentive and capacity to abuse SEPs after selected as a standard technology. In this situation, FRAND commitment becomes more and more significant because it can play a role as an institutional complement for competitive constraints which are artificially removed.

In order to harmonize with patent law objectives, it is necessary to require proving of exceptional circumstances supporting anti-competitiveness. However, the degree of proving could be eased in the situations of FRAND commitment infringements. ${ }^{20}$

\subsection{Theories and establishment of Competitive Harm}

\subsubsection{Theories of Competitive Harm}

Theories of competitive harm means theoretical frameworks explaining mechanism that the effects on markets arising from an enterprise's conduct give rise to weakening of competitive constraints or competitive pressure deriving from competitors or trading partners. Such theories should (i) be logically consistent, (ii) reflect the incentives that various parties face, (iii) be in line with the available empirical evidence, and (iv) articulate how consumers have been/will be harmed. ${ }^{21}$

\footnotetext{
${ }^{20}$ Bjorn Lundqvist, 'The Interface between Competition Law and Standard Essential Patents Some Early Comments on the Huawei Case' (2015) European Competition Journal $371<\mathrm{https} / / /$ ssrn.com/abstract=2688257> (stating that the situation in which an SEP holder subject to FRAND commitment refuses to license on FRAND terms triggers new exceptional circumstance doctrine). ${ }^{21}$ Hans Zenger and Mike Walker, 'Theories of Harm in European Competition Law: A Progress Report' in Jacques Bourgeois and Denis Waelbroeck (eds), Ten Years of Effects-Based Approach in EU Competition Law (Bruylant 2012).
} 
Such theories are also combined with counterfactual method by which the current situation is compared with the hypothetical competitive situation. ${ }^{22}$

Theories of competitive harm can be classified as follows. More economic theories include predation analysis framework, raising rivals' cost analysis framework, anticompetitive foreclosure analysis framework, and leveraging of market dominance analysis framework. More normative theories include discrimination analysis framework, entry barrier analysis framework, exclusivity analysis framework, and essential elements analysis framework.

In two cases, the KFTC attempted to explain the competitive constraints by using various theories of competitive harm. In the 2 nd case, based on raising rivals' costs analysis framework, ${ }^{23}$ the KFTC presented an increase in competitors' costs resulting from Qualcomm's threats of attack on patent infringements and patent umbrella effects $^{24}$ as one of the grounds for anticompetitive effects. The leveraging of market dominance analysis framework ${ }^{25}$ was used in both cases. One-way leveraging was concerned in the 1st case (leveraging from the technology market to the component market), while cross leveraging was contemplated in the 2 nd case (leveraging from the technology market to the component market and vice versa). In the 2 nd case, both offensive leveraging and defensive leveraging ${ }^{26}$ were also concerned.

Discrimination analysis framework was primarily concerned with the 1 st case of infringements of the non-discriminatory element of FRAND, but in the 2nd case, this framework was also relied upon as the effect of discriminating between Qualcomm's modem chipset purchasers with patent umbrella and purchasers of rival companies without it. The KFTC also used the essential elements analysis framework, which is based on recognizing SEPs as essential elements. ${ }^{27}$

\footnotetext{
${ }^{22}$ For a general explanation about the use of the counterfactual method in EU competition law, See Damien Geradin and Ianis Girgenson, 'The Counterfactual Method in EU Competition Law: The Cornerstone of the Effects-Based Approach' (December 2011) <http://ssrn.com/abstract=1970917>.

${ }^{23}$ Steven Salop and David Scheffman, 'Raising Rivals Costs' (1983) 73 American Economic Review 267; Thomas G. Kattenmaker and Steven C. Salop, 'Anticompetitive Exclusion: Raising Rivals' Costs to Achieve Power over Price' (1986) 96 Yale Law Journal 209.

${ }^{24}$ KFTC (n 14) 9.

${ }^{25}$ Daniel L. Rubinfeld, 'Antitrust Enforcement in Dynamic Network Industries' (1998) Berkeley Law Scholarship Repository 859 (explaining that leveraging occurs when a firm uses its advantage from operating in one market to gain an advantage in selling into one or more other, generally related markets).

${ }^{26}$ Offensive leveraging is about reaping additional monopoly rent from a second market, while defensive leveraging is about an attempt to defend the primary dominant position; Directorate-General for Internal Policies, 'Challenges For Competition Policy in a Digitalised Economy’ (Study, July 2015) <https://www.researchgate.net/publication/290429309_Challenges_ for_Competition_Policy_in_a_Digitalised_Economy>.

${ }^{27}$ This seems to be a change from an earlier position in Samsung $v$ Apple, in which the KFTC held that telecommunications SEPs were not an essential element, explaining that SEP holders are subject to a FRAND licensing obligation, and that since there are multiple SEP holders and thousands of SEPs for a cellular standard, it is different from a case where there is only a single essential element; Korea Fair Trade Commission, 'KFTC Determines That Samsung Electronics'
} 
The KFTC also considered these adverse effects collectively because it has the effect of reinforcing each other through the feedback effect. The KFTC even attempted to compare Qualcomm's practice with SEP holder's injunction against willing licensees. ${ }^{28}$ In view of the KFTC, Qualcomm's practice is worse than such an injunctive measure in terms of the nature and degree of competitive harm.

\subsubsection{Extent of Proving Competitive Harm}

The KFTC focuses on exclusionary effects as opposed to exploitative effects. Finding special circumstances in both cases may have affected articulating theories of competitive harms as well as setting up the extent of proving. The KFTC considered that three characteristics in relation to Qualcomm's business position and nature of conducts increased the likelihood that applicable theories of competitive harms could be really applied and thus decreased the extent of its proving. The three characteristics are (1) that the Qualcomm acquires dominant position through standard-setting and FRAND commitments, (2) that Qualcomm is vertically integrating enterprise dominant both in the technology market and the goods market, and (3) that breach of FRAND commitments results in elimination of institutional competitive constraints remaining in the SEPs license markets.

\section{Comparison with Other Jurisdictions}

Qualcomm cases have also been investigated and sanctioned by other competition authorities outside of Korea. Japan is the first country to deal with Qualcomm case. The Japan Fair Trade Commission (JFTC) acknowledged that in 2009, Qualcomm's conducts infringed the Japanese Antimonopoly Act (AMA). ${ }^{29}$ The National Development and Reform Commission (NDRC), one of China's three competition agencies, determined in 2015 that Qualcomm's conducts violated China's Antimonopoly Law (AML). ${ }^{30}$ In early 2017, the Federal Trade Commission (FTC) of the US filed a complaint against Qualcomm in Northern

\footnotetext{
Injunction Claim against Apple for Infringement of Standard Patents is not a Breach of the MRFTA' (2014).

${ }^{28}$ Case C-170/13 Huawei Technologies Co. Ltd v ZTE Corp. EU:C:2015:477.

${ }^{29}$ Japan Fair Trade Commission, 'Cease and Desist Order against QUALCOMM Incorporated' (30 September 2009) <http://www.jftc.go.jp/en/pressreleases/yearly-2009/sep/individual-000038. html>.

${ }^{30}$ Liyang Hou, 'Qualcomm: How China has Invalidated Traditional Business Models on Standard Essential Patents' (2015) Journal of European Competition Law \& Practice 686.
} 
District Court of California for violating Section 5 of the FTC Act. ${ }^{31}$ The Taiwan Fair Trade Commission (TFTC) joined the forces by imposing record fines of 23.4 billion Taiwan dollars (approximately 7.75 million US dollars) on Qualcomm for the violation of the Taiwan Fair Trade Act (TFTA) in October 2017. ${ }^{32}$ Most recently, the European Commission (EC) fines Qualcomm 997 million Euro for abuse of dominant market position by making significant payments to a key customer on condition it would not buy from rivals. ${ }^{33}$

In the following, the author compares the types of behaviors in Korea with Japan, China, and the US in turn, and examine the commonalities and differences between the four competition authorities in terms of theories of competitive harm.

\subsection{Korea in Comparison with Japan}

In comparison with Korea, Japan's focus was narrowed down to specific restrictive trading conditions such as provisions of royalty-free license to Qualcomm and non-assertion of patents against Qualcomm and, customers of Qualcomm imposed on Japanese manufacturers of subscriber units or base stations, many of which have been engaged in the research and development of wireless telecommunications technologies. This conduct type can correspond to imposing royalty-free cross-grant terms in Korean 2nd case which was determined as unfair and unreasonable (Table 1).

\subsection{Korea in Comparison with China}

In China, three types of abusive behavior were examined, which were respectively (1) charging unfair high royalties, (2) tying non-SEPs license with license to SEPs, and (3) imposing unreasonable conditions in the sale of baseband chipsets. The first

\footnotetext{
${ }^{31}$ Federal Trade Commission, 'FTC Charges Qualcomm With Monopolizing Key Semiconductor Device Used in Cell Phones (17 January 2017) <http://www.ftc.gov/news-events/press-release/ 2017/ftc-charges-qualcomm-monopolizing-key-semiconductor-device-used >; Sivinski (n 13).

${ }^{32}$ Andy C. M. Chen, 'Investigation Competition Cases In Taiwan: Procedural Perspective' (Competition Policy International, 2017) < https://www.researchgate.net/publication/316685925_ Investigating_Competition_Cases_in_Taiwan_the_Inquisitorial_Principle_and_the_Abuse_of_ Superior_Bargaining_Position>. The types of behaviors in the TFTC case are (1) refusing to license competing chip makers its SEPs, (2) conditioning the sale of its chips to device manufacturers on their signing the patent licensing agreement, and (3) forcing competing chip makers to accept unfavorable terms, which are much the same as in the KFTC case.

${ }^{33}$ European Commission, 'Antitrust: Commission Fines Qualcomm €997 Million For Abuse Of Dominant Market Position' (24 January 2018) <http://europa.eu/rapid/press-release_IP-18-421_ en.htm>. Qualcomm's practices in this case are similar to the conduct of imposing conditional rebate in the first Korean case.
} 
Table 1 Comparison between Korea and Japan

\begin{tabular}{l|l}
\hline Korea $(2009,2017)$ & Japan (2009) \\
\hline Charging discriminatory royalties & \\
\hline Imposing conditional rebates & \\
\hline $\begin{array}{l}\text { Charging royalties over expired } \\
\text { patents }\end{array}$ & \\
\hline $\begin{array}{l}\text { Refusal or restriction of license to } \\
\text { competing chipset makers }\end{array}$ & \\
\hline $\begin{array}{l}\text { Linking chipset supply with license } \\
\text { to handset makers }\end{array}$ & $\begin{array}{l}\text { Royalty-free license and non-assertion-of-patent } \\
\text { provisions for manufacturers of semiconductor } \\
\text { integrated circuits etc. }\end{array}$ \\
\hline $\begin{array}{l}\text { Imposing unfair and unreasonable } \\
\text { terms with handset makers }\end{array}$ &
\end{tabular}

and second types of conduct find their equivalents in Korean cases. With regard to the first conduct type of charging unfair high royalties, two issues of charging royalties over expired wireless SEPs and requiring free cross-license from licensees made a basis of declaring Qualcomm's price as excessive. This can be compared with Korea's approach not relating the issues to excessive pricing. The second conduct type corresponds to comprehensive portfolio license issue as a part of the conduct type of unfair and unreasonable licensing terms with handset makers in Korean 2 nd case, which the KFTC did not label as tying. The third type of conduct includes the condition in the sale of baseband chipsets requiring not to challenge the patent licensing agreement, which was not explicitly considered in Korea (Table 2).

Table 2 Comparison between Korea and China

\begin{tabular}{l|l|l}
\hline Korea $(2009,2017)$ & \multicolumn{2}{|l}{ China (2015) } \\
\hline Charging discriminatory royalties & \multicolumn{2}{|l}{} \\
\hline Imposing conditional rebates & \multicolumn{2}{|l}{} \\
\hline Charging royalties over expired patents & $\begin{array}{l}\text { Charging unfair } \\
\text { high royalties }\end{array}$ & $\begin{array}{l}\text { Charging royalties over } \\
\text { expired SEPs }\end{array}$ \\
\hline $\begin{array}{l}\text { Refusal or restriction of license to } \\
\text { competing chipset makers }\end{array}$ & \multicolumn{2}{|l}{} \\
\hline $\begin{array}{l}\text { Linking chipset supply with license to } \\
\text { handset makers }\end{array}$ & $\begin{array}{l}\text { Requiring free } \\
\text { cross-license from licensees }\end{array}$ \\
\hline $\begin{array}{l}\text { Imposing unfair and unreasonable terms } \\
\text { with handset makers }\end{array}$ & $\begin{array}{l}\text { Charging unfair } \\
\text { high royalties }\end{array}$ \\
\cline { 2 - 2 } & \multicolumn{2}{|l}{ Tying non-SEPs license with license to SEPs } \\
\hline
\end{tabular}


Table 3 Comparison between Korea and US

\begin{tabular}{l|l}
\hline Korea $(2009,2017)$ & US Allegation (2017) \\
\hline Charging discriminatory royalties & \\
\hline Imposing conditional rebates & \\
\hline Charging royalties over expired patents & $\begin{array}{l}\text { Refusal to license at component } \\
\text { level }\end{array}$ \\
\hline $\begin{array}{l}\text { Refusal to or restriction on license to } \\
\text { competing chipset makers }\end{array}$ & No license, no chips policy \\
\hline Linking chipset supply with license to handset makers & \\
\hline $\begin{array}{l}\text { Imposing unfair and unreasonable terms } \\
\text { with handset makers }\end{array}$ & De facto exclusive dealing with Apple \\
\hline
\end{tabular}

\subsection{Korea in Comparison with US: Conduct Types}

The FTC's complaint makes three major allegations concerning Qualcomm's anticompetitive behavior, which refers to (1) refusal to license at component level, (2) no license, no chips policy, and (3) de facto exclusive dealing with Apple. The first and second types of conduct can be matched with those of the Korean 2nd case. Both authorities adopt similar approach in that they derive theories of harm through Qualcomm's course of conduct. ${ }^{34}$ The third type of conduct is a specific issue in the US (Table 3).

\section{Conclusion}

In terms of theories of harm, Korea focuses on exclusionary effects with Japan and US, while China focuses on exploitative effects. Korea, Japan and US focus on exclusionary effects in common, but differ in emphasis.

Korea applied the abuse of dominance clause under the MRFTA and challenged the SEPs license markets and chipset markets. In the US, the FTC alleged that Qualcomm's conducts were to maintain monopoly power or foreclose competition, and the allegation was that the conducts would constitute the stand-alone violation of unfair methods of competition provision under the Section 5 of the FTC Act. Both authorities have the common ground in that they found harm to competition from a refusal to license at the component level. ${ }^{35}$ In contrast, Japan challenged

\footnotetext{
${ }^{34}$ Koren Wong and others, 'A Comparative and Economic Analysis of the US FTC's Complaint and the Korea FTC's Decision against Qualcomm' (2017) Competition Policy International Antitrust Chronicle <https://www.competitionpolicyinternational.com/wp-content/uploads/2017/ 04/CPI-Wong-Ginsburg-Layne-Robins-Slonim.pdf>.

${ }^{35}$ ibid.
} 
Qualcomm's behavior as impediment of fair competition in the technology market because the JFTC applied the unfair trade practices clause under the AMA.

China focuses on exploitative effects unlike other countries. The reason seems to be that the NDRC mainly covers price-related antitrust enforcement. Exploitative effects on handset makers were recognized, taking various factors such as facilitating price increase (including expired SEPs) and preventing price decrease (excluding cross-license fee) into consideration. Exclusionary abuse character was also found, but unclear on whom it affects.

Disclosure This work was supported from the Ministry of Education of the Republic of Korea and the National Research Foundation of Korea (NRF-2016S1A3A2923769). 
Open Access This chapter is licensed under the terms of the Creative Commons Attribution 4.0 International License (http://creativecommons.org/licenses/by/4.0/), which permits use, sharing, adaptation, distribution and reproduction in any medium or format, as long as you give appropriate credit to the original author(s) and the source, provide a link to the Creative Commons license and indicate if changes were made.

The images or other third party material in this book are included in the book's Creative Commons license, unless indicated otherwise in a credit line to the material. If material is not included in the book's Creative Commons license and your intended use is not permitted by statutory regulation or exceeds the permitted use, you will need to obtain permission directly from the copyright holder.

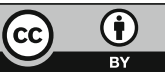

